\title{
UNA MUESTRA DE LA VIGENCIA DEL TEATRO ESPAÑOL EN PORTUGAL DURANTE LA PRIMERA MITAD DEL SIGLO XVIII *
}

\author{
Piedad Bolaños Donoso \\ y Mercedes de los Reyes Peña
}

Entre las obras inéditas del escritor portugués Tomás Pinto Brandão (1664-1743), poeta popular por excelencia en su época, hemos hallado una composición dotada de singular interés para ilustrar la vitalidad de nuestro teatro áureo en Portugal durante una época que sobrepasa los límites cronológicos de su anexión a España (1580-1640) ${ }^{1}$. Se trata de la « «Relassaõ da comedia También si [sic] ama en el Abismo, traduzida em Portuguez E aplicada a hû bofetaõ que a Segunda Dama da comedia, a pequena, deu na Primera, a grande, dentro no vestuario», como figura en la página que precede al texto en el manuscrito donde se ha conservado ${ }^{2}$. Estas palabras, que no sabemos si pertenecen al autor o al

* Este artículo forma parte de un trabajo más amplio en curso de realización sobre las representaciones teatrales castellanas en Portugal durante el Siglo de Oro, tema central de una Acción Integrada entre el Instituto de Cultura Española de la Universidad de Lisboa y el Departamento de Literatura Española de la Universidad de Sevilla.

1 No es el primero ni el único texto que nos confirma esta presencia del teatro español en Portugal, en esa época. Recordemos, a título de ejemplo, la «Informação da Companhia de Comedias de $\overline{\mathrm{q}}$ he autor Ferrer, $\overline{\mathrm{q}}$ este anno de 1710 representa no patio de Lxa» (Biblioteca Nacional de Lisboa, COD. 8691: Miscellanea litteraria. Prosa e verso), citada por José da Costa Miranda en su artículo: "Acerca do teatro espanhol em Portugal (século XVIII): alguns apontamentos críticos da Mesa Censória» (Bracara Augusta, XXXII, Fasc. 73-74 (1978), págs. 371-82, págs. 371-72) y que fue publicada por José Gonçalves Ribeiro Guimarães (Jornal do Commercio, n. 6612 (18 de noviembre de 1875), n. XXXI). El patio de comedias que aparece en la Información es el de la rua das Arcas, al que también se refieren los documentos coetáneos con las denominaciones de Pateo das Comedias o Pateo de Lisboa, como ocurre en este caso.

2 Obras Poeticas/das que deixou manuscriptas/Thomaz Pinto Brandâo/ Devididas em Quatro Tomos / [...] Tudo adquerido pelo decurso de annos, e parte conferi/do por outras copias; [...] Por Antonio Correya Vianna/ Lisboa, 1776 (Ms. 8589 de la Biblioteca Nacional de Lisboa), pág. 557. 
colector - Antonio Correya - aunque nos inclinamos más por la primera hipótesis, van seguidas por otras que debemos atribuir al segundo: «Isto he da Companhia de Castelhanos que antigamente, e antes do Terremoto de 1755, reprezentavam no Pateo das Comedias, que era na Rua das Arcas» ${ }^{3}$, pues Pinto Brandão había fallecido antes del seísmo.

Si la mala calidad de los versos pudo haber sido un freno para su publicación (el autor no incluye esta obra en el primer volumen de sus Poesías, $1732^{4}$, ni en la reimpresión hecha en 1733, corrigiendo los muchos errores de la primera ${ }^{5}$ ), su valoración estética no ha sido óbice, en este caso, para darlos por primera vez a la imprenta ${ }^{6}$, pues, su escaso mérito poético se ve compensado por su importancia como testimonio de la presencia de las compañías castellanas en Portugal, de la vida que tuvo el teatro español en Lisboa y de la paródica actitud de un escritor portuense ante el mismo. De un escritor que, además, lo conocía muy bien por su continua relación con el mundillo de la farándula, hasta el punto de irse a residir a la «Rua das Arcas», calle donde se encontraba el «patio de comedias» de ese nombre ${ }^{7}$.

Aunque Gustavo de Matos Sequeira califica a Pinto Brandão como «o mais galanteador de cómicas de que existe memoria» ${ }^{8}$, fue también poeta muy de su época que dejó, junto a bellas composiciones dirigidas a famosas actrices, otras donde su vena satírica e irónica emerge a la superficie, inundándolo todo. Ribeiro Guimarães destaca precisamente esta última faceta, cuando afirma que fue «o poeta theatral do tempo, mas não a moda dos modernos, porque na suas poesias resaltava sempre a facecia, e quasi sempre a ironia» ${ }^{9}$. Tal es el caso, por ejemplo, de su Comedia de comedias, pieza de circunstancia escrita en español con motivo de la despedida de una compañía castellana que representaba en el Patio de las Arcas, ante la llegada de otra desde Valencia, donde los papeles desempeñados por los actores son los títulos de las comedias más famosas del momen-

3 Idem.

4 Pinto/ renascido, /empennado, e desempennado:/ Primeiro voo, / Dirigido ao Excellentissimo Senhor/ Dom Luis Joze/ Leonardo de Castro/ Noronha Ataide e Sousa, / Undecimo Conde de Monsanto, / Composto por/Thomaz Pinto Brandam./ Lisboa Occidental,/ Na Officina da Musica./ M.DCC.XXXII.

5 Pinto/ renascido, / empennado, e desempennado/ primeiro voo, / Novamente emendado dos muitos erros da pri/meira impressaõ. Dirigido ao Excellentissimo Senhor/D. Luiz Joseph/Leonardo de Castro/ Noronha Ataide e Sousa, / Undecimo Conde de Monsanto, / composto por/ Thomaz Pinto/ Brandam. / Lisboa Occidental,/ Na Officina de Joseph Antonio Da Sylva,/ Impressor da Academia Real/ M.DCC.XXXIII./ Com todas as licenças necessarias.

6 Esta composición no figura tampoco en la edición póstuma de Pinto renascido.... (Lisboa: Na Officina de Pedro Ferreira, 1753) ni entre los folletos del autor conservados en diversas bibliotecas portuguesas.

7 Cf. José Gonçalves Ribeiro Guimarães, «Memorias para a historia dos theatros de Lisboa», Jornal do Commercio, no 6658 (15 de enero de 1876), XXXVI.

8 Gustavo de Matos Sequeira, Teatro de outros tempos. Elementos para a História do Teatro Português (Lisboa: 1933), pág. 229.

9 José Gonçalves Ribeiro Guimarães, «Memorias para a historia dos theatros de Lisboa», Jornal do Commercio, n. 6658 (15 de enero de 1876), XXXVI. 
to ${ }^{10}$. Ya en ellos se aprecia esa vertiente cómica y satírica que aparece más potenciada en el texto que publicamos: Juan López, "Barba», hacía Las canas en el papel; Diego de León, «Vejete», D. Diego de noche; la Señora Mariana, «que era gangoza», La desdicha de la voz; la hija del Barba, Abrir el ojo, teniéndolo ella «medio cerrado», etc. ${ }^{11}$.

En esta misma línea hay que situar nuestra composición, versión burlesca de un largo romance perteneciente a la Jornada Primera de la comedia También se ama en el abismo del dramaturgo español Agustín de Salazar y Torres (1642-1675), cuyo asunto se transpone a un incidente tan trivial y episódico como es el de una riña de actrices entre bastidores, ambiente que Pinto conocía muy bien. Aunque la lejanía temporal que nos separa del texto haga perder muchas de las alusiones que encierra, es evidente que estamos ante una clara parodia -escatológica y obscena en más de una ocasión- ${ }^{12}$ de ese teatro representado por compañías castellanas en el Patio de las Arcas, local construido siguiendo el modelo de nuestros "corrales» de comedias, donde se desarrolló de forma casi hegemónica toda la actividad dramática pública de la capital lisboeta, desde su apertura a finales del siglo XVI ${ }^{13}$, hasta poco antes de su desaparición con el terremoto (1755).

Si el hallazgo del romance portugués nos ha permitido poner en relación la obra de Tomás Pinto con la de Agustín de Salazar y editar en paralelo un texto de cada escritor, el estudio de sus respectivas biografías obliga también a establecer ciertas similitudes entre ellos. Los dos emigran a las Indias, donde permanecen un período importante de sus vidas. El dramaturgo español fue llevado a Nueva España desde corta edad con su tío D. Marcos de Torres, obispo de Campeche que murió siendo virrey de México, para recibir una educación esmerada. Pinto Brandão, por distintas circunstancias, partió para Bahía a finales de 1680 , con el propósito de «assentar praça no terço da guarnição da cidade» ${ }^{14}$.

Parte de la producción de ambos es también resultado de un común denominador: el hacer una poesía de estilo joco-burlesco. Por lo que respecta al autor español, basta con repasar la relación de obras que su amigo D. Juan de Vera

10 Puede leerse en Thomaz Pinto Brandam, Pinto renascido... (Lisboa Occidental: 1732), págs. 530-559; (1733), idem; (1753), págs. 393-414, comedia cuya reedición preparamos.

11 Idem, págs. 530-31 y 393-94, respectivamente.

12 La parodia dramática, género al que pertenece la Relassaó de Tomás Pinto, fue bastante cultivada en nuestra literatura barroca. Junto a comedias, loas, entremeses y bailes sometidos a un tratamiento burlesco, aparecen también «trovas» y «relaciones jocosas» que «suelen ser —en palabras de Salvador Crespo Matellán - parodia de pasajes aislados de otras composiciones dramáticas, de ordinario de comedias sobradamente conocidas» (La parodia dramática en la literatura española (Salamanca: Universidad, 1979), pág. 17), tipo este último donde quedaría encuadrado el Romance de Pinto Brandão.

13 En 1591, el Hospital Real de Todos os Santos contrató con Fernando Díaz de la Torre la edificación de dos patios de comedias, pero sólo se erigió el de las Arcas que funcionaba ya en 1594, pagando las tres quintas partes de su rendimiento al Hospital, según una fórmula importada también de Castilla (Cf. Gustavo de Matos Sequeira, Teatro de outros tempos..., ob. cit., págs. 82-83).

14 Tomás Pinto Brandão, Antología. Este é o bom governo de Portugal. Prefácio, leitura de texto e notas de João Palma-Ferreira (Lisboa: Publicações Europa-América, 1976), pág. 5. 
Tassis dice que le logró recoger y no publicó: «...y una comedia burlesca [...] Dos fábulas joco-serias, una en octava y otra en un romance [...], poesías diferentes, sacras, heroicas, líricas, amorosas y burlescas» ${ }^{15}$, aunque Salazar, también es cierto, no alcanzó precisamente la fama por este tipo de composiciones. En este punto se diferencia de él su coetáneo Pinto Brandão. Producto típico de finales del siglo XVII y primeras décadas del XVIII, Pinto canta los principales sucesos de la corte con una pluma mordaz, al mismo tiempo que jocosa; es bohemio y polémico; retrata las miserias y dedica su obra, casi en su totalidad, a la labor de los hombres del poder, al Rey y a la nobleza. Fue lo que se dice un poeta satírico que supo denunciar las injusticias sociales, consiguiendo con este tipo de composiciones el mayor de los éxitos. Como muestra basta citar su gran obra Este é o Bom Governo de Portugal. A pesar de que su crítica está más encaminada a la clase dominante que al pueblo, no rehusa poner bajo su pluma las preocupaciones sociales que podían surgir en un momento determinado ${ }^{16}$. A esta actitud por aprehender en su poesía acontecimientos del momento, responden muchas de sus composiciones de temática teatral ${ }^{17}$, que constituyen un valioso testimonio para la reconstrucción del ambiente y de la historia del drama en su época.

Una vez esbozadas algunas facetas de la personalidad de estos autores, interesa saber dónde pudo tener Pinto Brandão conocimiento de la producción dramática de Salazar y, en particular, del romance aquí objeto de estudio. ¿Sería durante su permanencia en América (estuvo en Brasil hasta 1695 como mínimo, desde donde pasó a Angola, volviendo a Río de Janeiro antes de su regreso a Portugal en $1703^{18}$ ), tierras a las que podría haber llegado alguna edición de la comedia y donde Salazar había sido representado y admirado a finales del siglo XVII en el Coliseo mexicano ${ }^{19}$ ?. No parece probable. En cambio, lo es mucho más la posibilidad de que dicho conocimiento fuese fruto del trasvase cultural $-\mathrm{y}$ sobre todo teatral- existente en la Península entre España y Portugal durante el siglo XVII y parte del XVIII.

15 Poetas líricos de los siglos XVI y XVII, t. II. Colección ordenada por D. Alonso de Castro (Madrid: Atlas, 1957 (BAE, XLII)), pág. LXIV. El subrayado es nuestro para mostrar la coincidencia del tono y la métrica de esta fábula con los de la composición de Pinto Brandão que aquí se publica. En 1975, Thomas Austin O'Connor publicó un artículo titulado «Don Agustín de Salazar y Torres: A Bibliography of Primary Sources" (Bulletin of Bibliography and Magazine Notes, XXXII (1975), págs. $158-61,167$ y 180), donde vuelve a recoger esas obras jocosas que, a pesar de no haber sido encontradas, no se duda de su composición.

16 Cf. Tomás Pinto Brandão, Antología..., ob. cit., págs. 9-10.

17 He aquí algunos ejemplos: «A huma Comedia domestica, intitulada: Opponerse a las Estrellas, que se representou em casa de Joào Correa Manoel, toda de mossas graves, e bonitas»; «Reposta a huns Titulos de Comedias, que aqui sahiraò, em huma folha de papel, applicados mal às Senhoras de Lisboa; que alguma o attribuhio a obra de Thomaz. Pinto: feja pelo amor de Deos»; "A huma Comediante chamada Rosa, e por outro nome a Gallega, cousa singularissima na graça com que canta, ou Italiano, ou Castelhano, ou Portuguez»; la ya citada Comedia de comedias (Thomaz Pinto Brandam, Pinto renascido..., ob. cit., ed. de 1733, págs. 92-93; 96-102; 329-30; 530-59, respectivamente); la "riña» de actrices motivo del presente trabajo, etc.

18 Cf. Tomás Pinto Brandão, Antología..., ob. cit., págs. 5-6.

19 Cf. Hildburg Schilling, Teatro profano en la Nueva España [Fines del siglo XVI a mediados del siglo XVIII] (México: Imprenta Universitaria, 1958), pág. 156. 
Recordemos que Pinto Brandão desde su vuelta a Lisboa frecuentó el teatro y estuvo en estrecha relación con los comediantes del Patio de las Arcas sobre los que escribió numerosas poesías laudatorias y satíricas, que Ribeiro Guimarães considera compuestas en su mayor parte entre 1723 y 1729 , últimos años de la vida activa del Patio ${ }^{20}$. Y precisamente durante esas tres primeras décadas del siglo XVIII, tras su reconstrucción motivada por un incendio a finales del XVII, el citado patio siguió recibiendo a compañías y a comediantes castellanos, que no sólo visitaban con asiduidad aquellas tierras sino que algunos, incluso, se establecieron en ellas de forma permanente. Antonio Ruiz, natural de Valencia, permaneció en Lisboa desde, tal vez, $1711^{21}$ hasta 1723 ó 1724 y, como él, otros más. Antonio Bela, que ya estaba en Lisboa desde 1718, es director de compañía, conjuntamente con José Ferrer, en $1723^{22}$. Este, que comienza a figurar como empresario de las compañías del Patio de las Arcas desde 1710, estuvo en Liboa hasta 1725 , dirigiendo sólo o en sociedad, como acabamos de ver, etc. ${ }^{23}$. ¿Le llegaría a Pinto Brandão el texto de Salazar a través de los comediantes españoles?. No es extraño que la comedia También se ama en el abismo se representara en Lisboa, igual que se había hecho en Madrid ${ }^{24}$. El hecho de que la obra de Pinto Brandão sea una parodia apoya esta suposición, pues éste es un género que requiere el conocimiento por el público de lo parodiado.

No obstante, las estrechas semejanzas existentes entre los textos del poeta portugués y del dramaturgo español (en metro, rima, forma estrófica, estructuras sintácticas, palabras, frases y hasta versos enteros) obligan a pensar que aquél debió tener delante el romance castellano. Esta cuestión tampoco resulta difícil, pues, además de su edición en la Cythara de Apolo, la comedia También se ama en el abismo se difundió impresa en colecciones de comedias de diversos autores

20 Cf. José Gonçalves Ribeiro Guimarães, «Memorias para a historia dos theatros de Lisboa», Jornal do Commercio, n. 6658 (15 de enero de 1876), XXXVI.

21 Desde 1710 según Casiano Pellicer, que ofrece una breve biografía del mismo en su Tratado histórico sobre el origen y progreso de la comedia y del histrionismo en España (Madrid: Imprenta de la Administración del Real Arbitrio de Beneficencia, 1804, Parte Segunda, págs. 27-28).

22 Cf. José Gonçalves Ribeiro Guimarães, «Memorias para a historia dos theatros de Lisboa» Jornal do Commercio, n. 6614 (20 de noviembre de 1875), XXXIII.

23 Idem, n. 6585 (16 de octubre de 1875), XXX.

24 N.D. Shergold y J.E. Varey documentan las siguientes representaciones de ella en Madrid durante el siglo XVII: cuatro palaciegas (el 21-sept.-1686, por Manuel de Mosquera y Rosendo López; el 12-dic.-1686, por Manuel de Mosquera; el 9-jun.-1691, por Damián Polope; y el 1-enero-1695, por Agustín y Damián Polope) y dos de corral (1 y 2-dic.-1695, por Carlos Vallejo, en el Corral del Príncipe), en Teatros y comedias en Madrid: 1666-1687. Estudio y documentos (Londres, Tamesis Books, 1975), pág. 191; Representaciones palaciegas: 1603-1699. Estudio y documentos (Londres, Tamesis Books, 1982), pág. 169; y Teatros y comedias en Madrid: 1687-1699. Estudio y documentos (Londres, Tamesis Books, 1979), págs. 292, 295 y 302. Recordemos que Agustín de Salazar, según su primer biógrafo y gran amigo D. Juan de Vera Tassis, fue tan querido y aplaudido en la corte que «a pocos dias [de su vuelta a la misma desde América y aprendizaje de Calderón] lograron sus comedias en esta Corte muchos merecidos aplausos, empleándole los primeros Señores della en las más célebres fiestas de sus Reales Magestades" (Agustin de Salazar y Torres, Cythara de Apolo, varias poesias divinas y hvmanas que escrivio... y saca a luz D. Ivan de Vera Tasis y Villarroel... En Madrid: A costa de Francisco Sanz, Impressor del Reyno..., 1681, sin n. de página). 
y en «sueltas» durante las tres últimas décadas del siglo XVII y en el siglo XVIII ${ }^{25}$. Pero aún hay más, el romance que sirve de fuente a Pinto Brandão se independizó de la comedia y circuló en pliegos sueltos ${ }^{26}$, siendo también objeto de versiones burlescas en castellano, como prueba la Relación bvrlesca de la comedia intitvlada: También se ama en el abysmo. Que saca a la pv́blica vergüenza el Bachiller Don Fermín Torbellino Falda Rota, Graduado en la Vniversidad de Majalahonda, y Académico del Pobretismo, llamado el «Infausto» (En Sevilla: por Francisco de Leefdael, en la Casa del Correo Viejo, s.a., 2 hs., $20 \mathrm{~cm}$.) ${ }^{27}$. Finalmente, la datación de la Relación portuguesa podría situarse en el período de tiempo comprendido entre 1703 (año del regreso de Pinto Brandão a Lisboa y en el que ya funcionaba el Patio de las Arcas reconstruido tras el incendio $^{28}$ ) y una fecha anterior a 1721, año en el que la actriz Petronila Xibaja, una

25 Véanse las ediciones de esta comedia recogidas por Thomas Austin O'Connor, en «Don Agustin de Salazar y Torres: A Bibliography of Primary Sources», art. cit., págs. 160-61.

26 Véase Francisco Aguilar Piñal, Impresos sevillanos del siglo XVIII. Adiciones a Tipografía Hispalense (Madrid, C.S.I.C., 1974), n. 1690 y M. Cruz García Enterría, Sociedad y poesía de cordel en el Barroco (Madrid, Taurus, 1973), pág. 348.

27 Aunque los argumentos de esta transposición burlesca y la de Pinto Brandão son diferentes (el rescate de una horrible gallega encenagada en un pantano, como explicación a la sarna que sufre el narrador; y una riña de actrices, respectivamente), las dos composiciones tienen ese aire común derivado de parodiar una misma obra y de un evidente gusto por la escatología y por el exceso en la deformación caricaturesca. Valgan como ejemplo, estos versos correspondientes a la descripción de la gallega, que tienen su paralelo en los vs. 81-99, 103-10 y 115-22 de Pinto Brandão:

Negro hollín era su pelo
en puerco, vntoso desorden,
pringue la frente, que al gusto
rancios le da chicharrones:
aora colige tú
desta cozina de horrores,
qué echaría del sobaco,
vertiendo la frente arrope?
. . . . . . . . . . . . . . . .
Su vista ahogó dos mil niños,
enturbió agua, secó flores,
mató pollos, y aun es poco
veneno en ojos tan torpes.
No sus niñas, sus lagañas
sólo es razón que te copie,
que no es tratable el veneno,
sí el vaso que lo recoge.
Y en fin, porque de sus ojos
te diga las perfecciones,
son puercos, vizcos, pequeños;

vertiendo la frente arrope?

\begin{abstract}
Sus dos labios, que pudieran servir de getas por moldes (que de cebolla su aliento hediondas eructaciones echa al ayre) tan crecidos son en su boca esportones, que parece que al abrirlos, la Cima de Cabra rompe. No sin grande sarna el pecho permite el diablo se adorne de vnas cerdas como zarzas, de vnas tetas como montes, porque en Galicia se admire que puedan tener conformes, si en las tetas dos montañas, en los sobacos dos bosques.
\end{abstract}

(Ob. cit., Bibl. Nac. de Madrid, V.E. caja $385(85)$ ).

¿Conocería Pinto Brandão esta Relación burlesca?. No lo sabemos, pero no debe olvidarse que estas transposiciones y los procedimientos para lograrlas eran de dominio común en una época en la que abundaba la literatura de carácter burlesco.

28 Comenzó a funcionar el 12 de abril de 1700, primera octava de Pascua (Cf. José Gonçalves Ribeiro Guimarães, "Memorias para a historia dos theatros de Lisboa», Jornal do Commercio, n? 6582 (13 de octubre de 1875), XXVIII). 
de las protagonistas de la «riña» (véase la nota 35), estaba de vuelta en Madrid después de haber residido muchos años en Lisboa ${ }^{29}$.

\section{Nuestra edición}

Para el texto de Pinto Brandão, hemos seguido el Ms. 8589 de la Biblioteca Nacional de Lisboa (págs. 558-569). En él, Antonio Correya Viana recoge, con clara escritura, en 1776, una serie de obras de dicho poeta bajo el título de Verdades / Pobres/ Ditas em/ Portugal, e nos Algarves, daquem, e dalem, / America, Africa e Ethiöpia. Este título fue el dado por Tomás Pinto a una ordenación que hizo de la Primera parte de sus obras (ofrecida al rey D. Juan V, en Lisboa Occidental, Año de 1717), anterior a la última selección de ella que imprimió con la denominación de Pinto renascido (Lisboa, 1732), como primer volumen de sus «Obras Poéticas».

En cuanto al texto de Agustín de Salazar (transcrito en paralelo para mostrar la fidelidad de Pinto Brandão respecto al mismo, hasta el punto de servirnos de ayuda para la mejor comprensión de algunos pasajes del romance portugués), el cotejo realizado entre diversas ediciones de la comedia y de sus relaciones ${ }^{30}$, y el texto portugués induce a pensar que el escritor portuense debió utilizar o una de estas relaciones no burlescas impresas en pliegos sueltos, como la realizada por Leefdael en Sevilla, o una "suelta" de la comedia igual o semejante a las salidas de las imprentas de Leefdael o de Padrino, donde el texto del romance castellano queda mucho más próximo al de Pinto que el de la comedia incluida en la Cythara de Apolo (1691 y 1694) ${ }^{31}$. Las similitudes entre el texto de la citada Relación

29 Cf. Idem, n. 6614 (20 de noviembre de 1875), XXXIV.

30 También se ama en el abismo, comedia famosa, en la Cythara de Apolo (Madrid: 1681), págs. 155-93 y (1694), págs. 150-86; También se ama en el abysmo. Comedia famosa (Sevilla: Imprenta Real, Casa del Correo Viejo, s.a., n. 180; este pie de imprenta pertenece a la de Francisco de Leefdael, que en 1733, habiendo ya fallecido éste, pasa a ser «Imprenta Real, Casa del Correo Viejo»: Cf. F. Aguilar Piñal, Impresos sevillanos del siglo XVIII..., ob. cit., pág. 15); Comedia famosa. También se ama en el abismo (Madrid: Imprenta de Antonio Sanz, Plazuela de la calle de la Paz, 1754, n. 261); Comedia famosa. También se ama en el abysmo (Sevilla: Imprenta de Joseph Padrino, Calle de Génova, s.a., n. 236); Comedia famosa. También se ama en el abismo (s.1., s.a., n. 199); Relación. También se ama en el abysmo, de D. Agvstín de Salazar (Sevilla: Francisco de Leefdael, en el Correo Viejo, s.a.); Relación bvrlezca de la comedia intitvlada: También se ama en el abysmo. Que saca a la pv́blica vergüenza el Bachiller Don Fermín Torbellino... (Sevilla: Francisco de Leefdael, Casa del Correo Viejo, s.a.).

31 He aquí algunos ejemplos:

\section{Pinto Brandão}

as ancias de duas Nimfas

pois portentoza descobre, toda de borras as fraldas, o cûme todo de humores,
"Relación...", impresa por Leefdael.

mis ansias, aunque es preciso,

pues portentoso compone toda de flores la falda toda la cumbre de ardores,
“Cythara de Apolo" (1694)

mis penas, aunque es preciso (pág. 153, col. 1)

que portentoso compone toda de flores la falda, el pecho todo de ardores, 
de Leefdael y el de Tomás Pinto, la presencia de la palabra «relación» (relassão) al frente de la composición portuguesa y ciertas consideraciones de orden cronológico han determinado nuestra elección de dicha Relación como texto paralelo al de Pinto Brandão ${ }^{32}$.

En la transcripción de ambos textos hemos guardado fidelidad absoluta a los originales utilizados, incluso en la puntuación por ser a veces también significativa. Las dificultades de comprensión derivadas en ocasiones de la extraña puntuación del texto portugués, se suplen en la traducción castellana, colocada a pie de página y concebida como medio de aproximación al contenido de la Relación de Pinto Brandão. Hemos procurado guardar en dicha traducción la máxima fidelidad a los versos de éste en todos los aspectos (métricos, fonéticos, sintácticos y léxicos). Cualquier alejamiento en favor de una más bella y fluida traducción castellana atenuaba las estrechas semejanzas existentes entre los dos textos cotejados y la literalidad de la transposición realizada por el vate portuense, aspecto que siempre hemos procurado destacar. Si bien nuestra traducción no respeta en muchas ocasiones la medida del verso, la publicamos bajo la forma gráfica de la poesía por las razones ya expuestas y para facilitar la localización de los versos portugueses en su versión castellana.

o peito todo de ransos;

(vs. 12-15)

Porque era: mas no retrato

que nâo he borrar Lombrigas, o pintar reinocerontes.

(vs. 79-80)

he justo só que te aponte,

lhe disse turbado: Féra

Pois a estes finos quartetos, aquele tirano Bode, como inadvertido alarve, desta maneira responde: Querem com atrevimentos estragar estes bigodes!

(vs. 171-76) el pecho todo de nieve,

(vs. 14-17)

(Porque era aqui tu atención,

(v. 123)

que no es comparar bellezas el referir perfecciones.)

(v. 129-30)

solo es justo que te copie,

(v. 150)

le dixe turbado: Hermosa,

(v. 207)

Porque a estos finos afectos:

Como, temerario joven, como, inadvertido amante, (la injusta beldad responde) quieres con atrevimientos malograr obligaciones?

(vs. 237-42) toda la cumbre de nieve, (pág. 153, col. 1)

porque es su beldad; la tuya

(pág. 154, col. 2)

pues no compara bellezas quien refiere perfecciones.

(pág. 154, col. 2)

solo es razon que te copie, (pág. 154, col. 2)

la dixe turbado: Hermosa

(pág. 155, col. 2)

pues a estos finos afectos la injusta beldad responde: Como, inadvertido amante, como, temerario joven, quieres con atrevimientos malograr obligaciones?. (págs. 155, col. 2 y 156, col. 1)

Las variantes del romance castellano en las ediciones de 1681 y 1694 de la Cythara de Apolo afectan sólo a la grafía.

32 Desde el punto de vista cronológico, la Relación de Leefdael no debe ser anterior a 1717, pues es a partir de esta fecha cuando se indica como domicilio «en la Casa del Correo Viejo, enfrente del Buen Suceso» (Cf. F. Aguilar Piñal, Impresos sevillanos del siglo XVIII..., ob. cit., pág. 15). Este límite cronológico permite jugar con la posibilidad de que esa Relación hubiera sido la consultada por Pinto, ya que queda dentro del período en el que creemos que se compuso la obra portuguesa. 
Romance $^{33}$

Sai o 1. Galan, e diz

[pág. Beliza: já que he forçozo, 558] que nesta occaziaô te conte as ancias de duas Nimfas, hum renovarem dolorem:

Escutai; mas com teu riro a minha historia naô borres; porâ. aos Escrivaêns suaviza a attensaô dos ouvidores. [pág. Na reprezentasaó varia 559] daquela Dama disforme, Pyramide de Cezilia; pois portentoza descobre, toda de borras as fraldas, o cûme todo de humores, o peito todo de ransos; por dar a entender aos Homêns, que entre as Mulheres tambem há seu Monstro de bigodes. Neste Promontorio (A Cristo!) Quem para tantos rancores, 20 para tanta obra, tivera tantas Muzas como nove!) Se occulta huma confiansa,
Ya que es forzoso, que en esta ocasion te informen mis ansias, aunque es preciso, que al referirlas se doblen, pues las que estàn en el pecho se duplican en las voces;

5 escucha, y en tu atencion mis ansias no se malogren, porque suavisa las penas la atencion de quien las oye. En el seno mas oculto

10 del Etna, aquesse disforme Piramide de Sicilia, pues portentoso compone toda de flores la falda, toda la cumbre de ardores,

15 el pecho todo de nieve, por dar à entender al Orbe, que en lo insencible también tienen los mostruos los montes. 20 En lo mas oculto (ha Cielos! Quien para immensos dolores, para immenso mal tuviera immensas explicaciones!)

Se obstenta un ameno balle,

\section{Romance}

Belisa, ya que es forzoso/ que en esta ocasión te cuente/ las ansias de dos ninfas,/ aunque el dolor se renueve,/ escucha, mas con tu risa $5 /$ no ensucies mi historia,/ porque a los escritores alivia/ la atención de los oyentes./ En la representación varia/ de aquella dama, disforme 10/ Pirámide de Sicilia,/ pues portentosa descubre/ toda de heces las faldas, / la cumbre toda de humores, / el pecho todo de hollín ${ }^{15}, /$ por dar a entender a los hombres/ que entre las mujeres también/ hay unos monstruos de bigotes,/ en este Promontorio ( $\mathrm{OOh}$ Cristo,/quién para tantos rencores ${ }^{20}, /$ para tanta obra tuviera/ tantas Musas como nueve!),/ se oculta una confianza,/

33 Agradecemos a la Dra. Da M. Victoria Navas y a D. José Alberto Osório Mateus, profesores de la Universidad de Lisboa y miembros de la Acción Integrada, la colaboración que nos han prestado en la revisión del texto portugués y de su traducción castellana. 
huma prosumpsaó se encobre, taô varia por seus narizes, [pág. por seus olhos taô enorme; 560] taô fertil por suas faces, e por seus beissos taô torpe; que neutrais muitos duvidam,

entre tantos Sabedores, se saô de Bezerro os zurros, se saô de Dragaô as vozes. Aqui cheguei huma tarde, quando pellos arredores, dezamparados de gente vi os mais dos camarotes:

Nem forsuras, nem meûdos; pois saô Comedias sem homéns, escassa Luz para vinho, pouca sopa para pobre. Apenas pois se acabáram do Quatro, as tiranas vozes;

[pág. quando a hû fatal zunido, 561] como de bofetaô dobre; e tal, que athé Joaô do Coito ${ }^{34} 45$ Lá o ouvio (o ouvio) dos Corredores: bolvendo todos as caras para onde os olhos ouvem; $\tan$ suave por sus olores,

tan fértil por sus crystales, por sus aves tan acorde, $\tan$ vario por sus matices, que en las dulces confusiones de Azucenas, y de Cisnes, de Rosas, y Ruyseñores, duda el oìdo à la vista

30 entre matices, y voces, si son fragrantes las Aves, si son canoras las flores. Aqui lleguè esta mañana, quando en tibios arreboles,

35 ni bien despierta el Aurora el rosado albor descoje;

mas tan confusa entre sombras, que neutral se mira el Orbe, ni luces, ni obscuridades, pues son tinieblas, y albores, escasa luz para dia,

40 corta sombra para noche. Apenas, pues, penetraba lo emmarañado del bosque, quando entre el tenaz latido de sabuessos, y ventores, escucho de una muger tiernas lastimosas vozes: vuelvo la vista, y diviso

una presunción se encubre,/ tan varia por sus narices, 25 / por sus ojos tan enorme,/ tan fértil por sus caras/y por sus labios tan torpe/ que, neutrales, muchos dudan,/ entre tantos sabedores, ${ }^{30}$ / si son de becerro los rebuznos, / si son de dragón las voces./ Aquí llegué una tarde,/ cuando por los alrededores,/ desamparados de gente 35 / vi la mayoría de los palcos:/ ni pequeños ni medianos,/ pues son comedias sin hombres,/ escasa luz para vino,/ poca sopa para pobre. $40 /$ Apenas, pues, se acabaron/ del cuatro las tiranas voces/ cuando, a un fatal sonido/ como de bofetón doble/ y tal que hasta Juan del Coito, 45 / allá lo oyó desde los corredores,/ volviendo todos las caras/ para donde los ojos oyen,/ 
vimos que hû fraco edificio

se arremessava a huma Torre, 50

Onde chegar naô podia

sem que por assalto fosse.

Isto era a Dama Lombriga

que á Dona Gibaya Fontes ${ }^{35}$

obrigava que ali désse

ternas Lastimozas vozes.
Acodio a Companhia;

hûns ás maôs, outros aos coices;

hûns dizendo $=$ Temte Nimfa:

[pág. Outros = detemte Faetonte. 562] un blanco bruto, que rompe

la diafanidad del ayre,

pues de sus huellas velozes,

no pudiendo dàr noticia

las mas avisadas flores, si fue vuelo, ò fue carrera

no se supo por entonces;

precipitaba una Ninfa

tan bella, pero perdone

por aora tu atencion,

que mientras el riesgo corre

estaran en los pinceles

desayrados los colores.

Desbocado bruto (dixe)

espera, no otro Faetonte,

60

à ruìna mayor el Orbe,

vimos que un flaco edificio embestía a una torre, $50 /$ donde llegar no podía/sin que por asalto fuese./ Esto era la dama Lombriz/ que a doña Gibaya Fuentes/ obligaba que allí diese 55/ tiernas lastimosas voces./ Acudió la compañía,/ unos a las manos, otros a las coces;/ unos diciendo: «Tente, ninfa»,/ otros: «Detente, Faetonte», 60/

35 Bajo el nombre de «Gibaya Fontes» creemos que se esconde el de una de las actrices de la «riña». En este caso, Pinto Brandão juega con la semejanza fonética de las palabras jibóia ('boa', 'serpiente de gran tamaño'), que opone a «lombriga" ('lombriz'), y Xibaja, apellido de la actriz Petronilla Xibaja, conocida por la Portuguesa, debido a su larga residencia en Lisboa. Muy bella y buena cómica, según unos, y desprovista de belleza y merecimientos, según otros (por ej. Francisco Xavier de Oliveira que, como indica Ribeiro Guimarães, la conoció personalmente), contó con las simpatías del rey $\mathrm{D}$. Juan $\mathrm{V}$, retirándose después a Madrid cargada de riquezas. Aquí se acomodó por los años de 1721 en la compañía de Antonio o José de Prado, con quien se casó. (Estas y otras noticias sobre la citada actriz pueden leerse en Casiano Pellicer, Tratado histórico sobre el origen y progreso de la comedia..., ob. cit., Parte II, págs. 119-34; Bartolomé J. Gallardo, Ensayo de una biblioteca española de libros raros y curiosos, Madrid: M. Rivadeneyra, 1863-89, 4 tomos, t. I, col. 670; José Gonçalves Ribeiro Guimarães, "Memorias para a historia dos theatros de Lisboa», Jornal do Commercio, $\mathrm{n}^{\circ}$ s. 6614 (20 de noviembre de 1875), XXXIV, y 6618 (25 de noviembre de 1875), XXXV; y N.D. Shergold y J.E. Varey, eds., Genealogia, origen y noticias de los comediantes de España, Londres: Tamesis Books, 1985, págs. 569-70). 
E taô presto se apartáram as duas Furias atrozes, que só hûms signais se vîram em brasso, bruto, e cagote. Assim pois como a hû Gigante acomete hum David pobre; e disso em que mais se funda ${ }^{36}$, lhe préga na testa hum golpe: Assim aquela Formiga á aquele Elefante dobre, em Lugar de sinco pedras, lhe pôz sinco dedos fortes. Enfadada pois a Dama, receyo, se a outra cólhe, que por tormenta desfeita, hum só tráque sosóbre; que si en el carro del Sol

abrasaron essos mobles, con un joven quatro brutos, què hara un bruto con dos Soles? dixe; y sacando la espada, al duro acerado corte tan presto cayò en el suelo, que amago, ruìna, y golpe, se executaron à un tiempo en brazo, bruto, e estoque.

65 Assi como alado rayo,

que hiriendo en altas torres, aunque es verdad, que es el trueno primero que los ardores, como es tan veloz la vista, y es el oido tan torpe, primero se vè el estrago, que el estallido se oye. Desmayada, pues, la Ninfa cayó en mis brazos turbòse todo mi valor, al vèr milagros tan superiores, y solo en mi pecho hablaron silencios, y admiraciones.

Y tan presto se apartaron/ las dos Furias atroces,/ que sólo unas señales se vieron/ en brazo, bruto y cogote./ Así pues, como a un gigante $65 /$ acomete un David pobre/ y con eso en que más se apoya/ le da en la frente un golpe,/ así aquella Hormiga/ a aquel Elefante doble, 70 / en lugar de cinco piedras/ le asentó cinco dedos fuertes./ Enfadada, pues, la dama,/recela, si a la otra coge,/ que, por tormenta descargada, $75 /$ a un solo pedo suyo zozobre./

36 Funda, como sustantivo significa 'honda'. La alusión a David permite al poeta portugués el empleo del sentido verbal y nominal del término funda. 
Assi como el caminante,

que incauto la huella pone en la grama, o en el cesped, que ardiente Vibora esconde, ya como flecha se vibre, ò ya como arco se enrosque, aquel subito peligro, que impensado reconoce, le embarga los movimientos, y le usurpa las acciones, sin saber huir el riesgo, por mas què el riesgo conoce. Assi yo, a tan impensado prodigio de amor immovil, por estatua me juzgara de bronce, ò marmol entonces: 110 mas luego dixe, sintiendo de su beldad los harpones, pues siento, no soy de marmol, y pues amo, no soy bronce. Si es la hermosura (decia) aquella musica acorde que no entienden los oìdos, y que los ojos la oyen: como tu, enigma divino, tu rara beldad compones, si hay contradicion hermosa de hermosas contradiciones?

[pág. Porque era: mas no retrato 563] a Segunda me perdoe,

que nâo he borrar Lombrigas, o pintar reinocerontes. Bello alvo era o cabelo em alvas de varios Lotes; e negra a testa, que á cara sóbra fazia de horrores.
(Porque era aqui tu atencion, este rato me perdone, sin que agravie tu hermosura el que su hermosura copie, que aquel que pinta una imagen, no es preciso que otra borre, que no es comparar bellezas

80 el referir perfecciones.) 130

Bella noche era el cabello en crespo undoso desorden, y Alva la frente, que al dia presta nevados candores.

Porque era... mas en el retrato/ la segunda me perdone,/ que no es ensuciar lom-

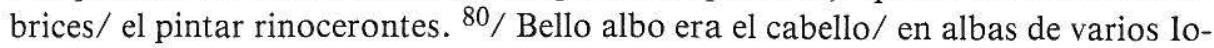
tes,/ y negra la frente, que a la cara/ sobra hacía de horrores./ 
Agora colige tu, entre taô densos vapores, onde he tenebrozo o dia, que bela serie a noite!

A vista deu sombra ao Mundo, Luto ao campo, olhado ás flores, 90 morte á gente, e inda he pouco o imperio do Lobizome ${ }^{37}$.

Nam seus olhos, seus argueiros ${ }^{38}$

[pág. he justo só que te aponte, 564] que eram olhos nunca vistos, 95 porque naô foram mayores: E emfim, porque de tais Luzes os hiperboles afroixe, Com naô serem nada, enfadam: Agora tu julgar pódes, sendo a Dama olho do cû, como seraô seus fedores.

Os dous beissos, que podéram ser já bordas de bispotes, de cujo bocejo, ou ásco, toda a Companhia foge:
85 Aora colige tu

de las dos contradiciones, como seria el Aurora en quien fuè bella la noche. Un arco la diestra empuña, dos en sus cejas descoje, dos de azabache, uno de oro, $\mathrm{y}$ en todos amor dispone, que de tres arcos que esgrime el que es dorado le sobre. Su vista diò luz al Cielo, vista al mar, sèr à las flores, muerte al amor, y aun es breve el imperio de sus soles.

No sus luces, sus reflexos solo es justo que te copie, que no es tratable la llama por serlo los resplandores. $\mathrm{Y}$ en fin, porque de sus ojos los hiperboles acorte, con los rigores alhagan:

aora tu reconoce, donde son las iras dulces, como seràn los favores.

Amor, y nieve su rostro mezclò en templados ardores, 160 que su beldad solo ha unido lo hermoso con lo discorde. Los dos labios, que pudieran ser incendio de los Dioses, 105 en cuyas asquas su aliento fragantes respiraciones

Ahora colige tú, ${ }^{85}$ entre tan densos vapores,/ donde es tenebroso el día/ ¡qué bella sería la noche!/ La vista dio sombra al mundo,/ luto al campo, aojo a las flores, 90 / muerte a la gente, y aún es poco/ el imperio de Lobizome./ No sus ojos, sus vigas/ sólo es justo que te indique,/ que eran ojos nunca vistos, 95 / porque no fueron mayores./ Y en fin, porque de tales luces/ las hipérboles afloje,/ con no ser nada, enfadan./ Ahora tú juzgar puedes, $100 /$ siendo la dama ojo de culo,/ ¡cómo serán sus hedores!/. Los dos bezos, que pudieran/ ser ya bordes de orinal,/ de cuyo bostezo o tedio 105/ toda la compañía huye,/

37 Lobisomem: 'hombre que, según la creencia popular, se transforma en lobo y vagabundea de noche' (J. Martínez Almoyna, Dicionario de Português-Espanhol, Porto: Porto Editora, s.a., pág. 769).

38 Clara alusión a la sentencia: «Ver a palha no olho do vizinho, nâo ver o argueiro no seu». 
Tanto nos ouvidos bûfam aqueles horrendos foles, que parecem dez trombetas, que os miolos abrem, e rompem.110 [pág. As maôs, por extravagancia, 565] negro ostentam, branco escondem; que todo aquele graô Turco a nenhum Solimaô sofre ${ }^{39}$. Naô sem arteficio, os peytos 115 saô dous cûs, mamas, ou Odres; porque a seus Marido diga: Ora chupa meus amores; E tambem porque se admire, que nelles conservar podem, 120 se em todo hum Abril, cabassas, em todo hû Inverno, alforges. presta à el ayre, tan purpureos en su boca los descoje, que parece en lo sangriento, que no los abre, los rompe. No $\sin$ artificio el pecho permite amor, que se adorne de claveles, que le vistan de jazmines, que le abrochen, porque en su pecho se admire, 175 que pudo tener conformes, si todo el Abril con nieve, todo el Invierno con flores.

A su imitación sus manos yelo obstentan, fuego esconden, 180 y lo que es yelo en los ojos, se muestra en el pecho ardores. Nueva cautela de amor, è indigna de que la logre, para vencer necesitan

tanto en las orejas bufan/ aquellos horrendos fuelles,/ que parecen diez trompetas/ que los sesos abren y rompen ${ }^{110}$./ Las manos, por extravagancia,/ negro ostentan, blanco esconden,/ que todo aquel gran turco/ ningún solimán soporta./ No sin artificio, los pechos 115 / son dos culos, mamas u odres,/ porque a su marido diga:/ "Ahora chupa, mis amores»/ y también porque se admire/ que en ellos mantenerse pueden 120 / si en todo un abril calabazas, / en todo un invierno, alforjas./

39 Como indica José Manuel Blecua en varias notas a las poesías satíricas de Quevedo, el solimán era un afeite para el rostro, llamado también «Gran Turco» (Francisco de Quevedo, Poesía original completa, ed., introd. y notas de J.M. Blecua, Barcelona: Planeta, 1981, pág. 583, n. 2., pág. 730 , n. 1, pág. 789 , n. 11). De aquí ese juego de palabras de Pinto Brandão (véase otro ejemplo en las décimas «A morte do conde de Monsanto, causada da água de Solimão que um boticário lhe deu em lugar de almeirão», en Tomás Pinto Brandão, Antología..., ob. cit., págs. 105-06), presente también en la poesía de Quevedo:

Que no tenga por molesto

en doña Luisa don Juan ver que, a puro solimán, traiga medio turco el gesto, $[\ldots]$

(Ob. cit., n. 668, pág. 730).

¿Tan soberbia me la tienen [a una dama] cuatro mudas y seis pasas del gran turco Solimán, con artificio preñadas?. 
No estreito daquelle talhe naô há homen que se afoge, que naô he melhor de fundo, 125 posto que de alto blazone.

\section{O mais dali para baixo}

[pág. he bandulho a trouxe mouxe, 566] de selada, rabo, e tripas, que carne ali naô se come. Os presuntos... Porem tanto me arrebato nos primores com que pinto ésta Serpente; que me esquesso, e naô me occorre de que ficou afrontada; Mas como desses ardores pode uzar sua paixaô, já que a minha a nada move, en mi historia, y su desmayo, allá buele, y acá non torne. Volveu pois do afrontamento; por signal, que Manuel Gomes, com vozes avinagradas, que falar puro naô póde,

[pág. por lhe faltarem os dentes 567] (verbi gratia, como nobis) lhe disse turbado: Féra barca infernal de Aqueronte; já estáz Livre: pero advierte, que do Hospital os Senhores huma injustissa fizeram em mandar vir de taô Longe

130

135
En lo estrecho de su talle no hay vida que no zozobre, no hay alma que no peligre, y para que mas te assombre, es carcel apetecida, siendo estrechas las prisiones.

En lo demás; pero tanto me arrebatan los colores con que pinto su hermosura, 195 que me olvido ciego, y torpe, de que quedò desmayada; mas como de essos errores sabe obrar una passion! $\mathrm{Y}$ pues la mia conoces, 200 en mi historia, y su desmayo ella vuelve y yo me cobre. Volviò, pues, del parasismo,

y con valbucientes vozes, porque la razon de amor se encuentra con las razones,

le dixe turbado: Hermosa, sacra deydad de estos bosques, ya estàs libre, pero advierte, que han permitido los Dioses una injusticia en mi pecho, pues viendo tus resplandores,

En lo estrecho de aquel talle/ no hay hombre que se ahogue,/ que no es mejor en lo hondo 125 / aunque en lo alto blasone./ El resto de allí para abajo/ es barriga a troche y moche/ cóncava, nalgas y tripas,/ que carne allí no se come. 130/ Los jamones.... Pero tanto/ me arrebato en los primores/ con que pinto esta Serpiente/ que me olvido y no me acuerdo/ de que quedó afrentada; 135/ mas como de esos ardores/ puede gritar su pasión,/ ya que la mía a nada conmueve/ en mi

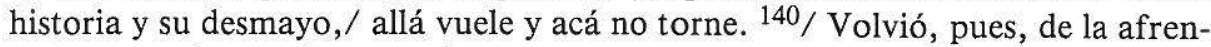
ta/ por señal, cuando Manuel Gomes/ con voces avinagradas,/ que hablar puro no pudo/ por faltarle los dientes 145 / (verbi gratia, como nobis), / le dijo turbado: "Fiera/ barca infernal de Aqueronte,/ ya estás libre, pero advierte/ que del Hospital los Señores 150 / una injusticia hicieron/ en mandar venir de tan lejos/ 
duas Damas, que só servem na Comedia de Estupores. Por donde, dize mofina, velha Deidade, por donde te trouxêram a ésta Terra, Monte acressentando a Montes?

Por bem conhecerte, filha, naô te ofenda este remoque, 160 este chasco naô te agrave, [pág. nem ésta surra te cósse. 568] Tambem eu cá tenho dedos, e como o tiro se Logre, o ár, indigno naô hé dezar para tais virotes. Moveu-se o Autor a isto, (que a isto muitos se movem) e emfim todos se afastáram, só Ella ficou immovel.

Pois a estes finos quartetos, aquele tirano Bode, como inadvertido alarve, desta maneira responde: Querem com atrevimentos estragar estes bigodes!

Se me mandáram buscar a todo o custo, e saô Nobres, [pág. ou me bebam, ou me vêrtam,

569] ou me alimpem, ou me borrem; 180 he perdido yo una vida, porque tu una vida logres.

155 Por donde, dime, divina 215 deydad, me heriste? Por donde entraron estos suaves apetecidos ardores?

$\mathrm{Si}$ es por los ojos, que son llaves de los corazones, què hechizo has puesto en los mios, que mirando tus dos Soles, conocen el riesgo, y mueren por lo mismo que conocen? Por no merecerte, Ninfa

no te ofenda, que te adore, no que te rueg[u]e te agravie, no el que te sirva te enoje, merezca otra vez tus brazos, que como el tiro se logre, el blanco indigno no es desayre de los harpones. Assi, pues, me lamentaba, moviòse el Cielo à mis vozes, moviòse el mar, mas la causa de mi dolor quedò immovil. Porque à estos finos afectos: Como, temerario joven, como, inadvertido amante (la injusta beldad responde)

175 quieres con atrevimientos malograr obligaciones?

Si has restaurado mi vida, $\mathrm{y}$ eres noble, reconoce,

dos damas, que sólo sirven/ en la comedia de fantoches./ ¿Por dónde, di.mohina, 155 / vieja deidad, por dónde/ te trajeron a esta tierra,/ monte acrecentando a montes?/ Por bien conocerte, hija,/ no te ofenda este remoque, 160/ esta burla no te agravie/ ni esta zurra te moleste./ También yo aquí tengo dedos,/ y como el tiro se logre/ el aspecto indigno no es 165 / desaire para tales virotes./ Movióse el autor a esto/ (que a esto muchos se mueven)/ y, en fin, todos se alejaron,/ sólo ella quedó inmóvil. 170/ Pues a estos finos cuartetos,/ aquel tirano bode/ como inadvertido salvaje/ de esta manera responde:/ "¿Quieren con atrevimientos 175 / malograr estos bigotes? / Si me mandaron buscar/ a toda costa, y son nobles,/ o me beban o me viertan,/ o me limpien o me ensucien, 180/ 
Ou me ponham em Castela outra vez; porque he adonde tenho o partido mais certo na Companhia dos pobres ${ }^{40}$.

Disse; e voltando a culatra, na mutassaô de dous montes, deu fim a sua Tragedia: Vossas mercêz me perdoêm. que ya quedas satisfecho, pues recompensas mayores no es possible hallar, que dar en que luzir à lo noble. $\mathrm{Y}$ aora, porque no acuses de tyranos mis rigores, una piedad anticipo, y es, que el desengaño logres aun antes de la experiencia, pues aviso à tus errores, que à mi esquivo pecho ofenden 255 hasta las adoraciones (dixo) y con veloces huellas, burlando mis intenciones me dexò. $[\ldots]^{41}$

El cotejo de textos realizado muestra la deuda del poeta portugués respecto al dramaturgo español. Menos extenso y vertido a otra clave, el romance de Pinto Brandão presenta tales analogías con el de Salazar y Torres que inducen a admitir que debió tenerlo delante. Clara prueba de que el teatro castellano, además de llegar a Lisboa como espectáculo, llegó también como lectura.

o me pongan en Castilla/ otra vez, porque es donde/ tengo el partido más cierto/ en la compañía de los pobres", / dijo, y volviendo las nalgas, 185 / en la mudanza de dos montes,/ dio fin a su tragedia./ Vuestras mercedes me perdonen.

40 ¿Sería ésta una irónica alusión a las riquezas que había allegado Petronila Xibaja?.

41 Esta relación tiene 37 versos más que Tomás Pinto no recoge; razones de espacio han aconsejado su omisión. 